\title{
Uma avançada proposta de reforma educacional no ultimo quartel do século XIX brasileiro: Leôncio de Carvalho e os Pareceres de Rui Barbosa
}

O trabalho faz um balanço da situação educacional no Brasil e na Bahia na década de 70 do século XIX, comparando-a com o censo de 1872. Relata sobre o gabinete liberal Sinimbu, em 1872, o seu Ministro do Império Leôncio de Carvalho e o seu "Decreto do ensino Livre" de 19 de abril de 1879. Menciona o encaminhamento deste à Comissão de Instrução Pública da Câmara de Deputados, provocando dois extensos pareceres redigidos por Rui Barbosa, comentando-os.

The work gives a balance os the educational situa ton at Brazil and os Bahia, in the seventies of the XIXth century. It talks about the Sinimbu's liberal boby of ministers, at 1978, and Leôncio de Carvalho the Empire Minister who renevwed the teaching with the so called "Free Teaching Decree" from april19th, 1879. This reform has been put into practice and conclucted to the Public Instruction Comission at the Deputies Chamber, where Rui Barbosa gave two extensive opinions about it, that are comented. 
A situação da educação

brasileira na década da 70 do

século XIX

A constituição brasileira de 1824 determinava, quanto à educação, e a instrução primária fosse gratuita, e uma lei em 15 de outubro de 27 preconizara a criação das escolas de primeiras letras que fossem cessárias em todas as cidades, vilas e lugares mais populosos. Nelas ensinaria:

a ler e escrever, as quatro operações de aritmética, prática de quebrados, decimais e proporções, as noções mais gerais de geometria prática, a gramática da língua nacional e os princípios da moral cristã e da doutrina da religião católica romana, proporcionadas à compreensão dos meninos; preferindo para as leituras a Constituição do Império e a História do Brasil.

Apesar da lei, no entanto, nem todas as escolas necessárias $\sim \mathrm{m}$ criadas por falta de professores. O ensino secundário era minis$: 10$ por Aulas avulsas, que permitiam ao estudante aprender a maté necessária para passar nos exames preparatórios para os cursos leriores. O curso superior no Brasil constava de duas Faculdades Medicina: uma na Bahia e outra no Rio de Janeiro, cada uma delas listrando dois cursos: o de Medicina e o de Farmácia; e duas Faculles de Direito: uma em São Paulo e outra em Olinda. (Só em 1874 riada a Escola Politécnica no Rio de Janeiro e, em 1875, a Escola v1inas, em Ouro Preto- NISKIER,1989;155/6).

Em 1834, o Ato Adicional à Constituição descentralizou o ensificando as províncias responsáveis pelo ensino primário e secuno, e o Império apenas pelo superior todo e demais níveis na capital laís, sede do governo (NUNES, 1999a;78).

Em 1854, no gabinete de conciliação presidido pelo Marquês de má, o ministro do Império, conselheiro Luiz Pedreira do Couto az, aprovara o regulamento da instrução primária e secundária pelo 'eto imperial, datado de 17 de fevereiro, e ele vigorou por bastante )0. ALMEIDA (1889;90) julga que nas prescrições do regulamento mifesta a idéia de fazer com que a organização pública do Rio de !ro (município neutro e sob jurisdição imperial por ser a capital do ,como visto) se tornasse um modelo para as províncias e, em ,eqüência, fosse se formando paulatinamente um sistema naciole instrução e de educação. 
No ano de 1870, reportando-se ao ano anterior, o relatório do ministro do Império do gabinete, presidido pelo Visconde de Itaboraí, Paulino José Soares de Souza, traz informações sobre o estado do ensino nas vinte províncias do Império que ALMEIDA $(1889 ; 120)$ resume na seguinte tabela.:

\begin{tabular}{|c|c|c|c|c|c|c|c|c|}
\hline \multirow{3}{*}{ Província } & \multicolumn{4}{|c|}{ Escolas Primárias } & \multicolumn{4}{|c|}{ Estabelecimentos de Ensino Secundário } \\
\hline & \multicolumn{2}{|c|}{ Pública } & \multicolumn{2}{|c|}{ Particular } & \multicolumn{2}{|c|}{ Pública } & \multicolumn{2}{|c|}{ Particular } \\
\hline & $\mathrm{n}^{\circ}$ & alunos & $\mathrm{n}^{\circ}$ & alunos & $n^{\circ}$ & Alunos & $\mathrm{n}^{\circ}$ & alunos \\
\hline Amazonas & 31 & 627 & 4 & 113 & I & 30 & I & 21 \\
\hline Pará & 106 & 4.710 & 57 & 608 & I & 140 & 7 & 726 \\
\hline Maranhão & 101 & 4.459 & 30 & 1.164 & 2 & 272 & 25 & 386 \\
\hline Piauí & 47 & 1.174 & 2 & 25 & 3 & 57 & 25 & 386 \\
\hline Ceará & 174 & 7.605 & 49 & 2.807 & 7 & 470 & 5 & 209 \\
\hline Rio G.Norte & 56 & 1.871 & 49 & 2.807 & 2 & 79 & 5 & 209 \\
\hline Paraíba & 103 & 2958 & 3 & 449 & 5 & 100 & I & 67 \\
\hline Pernambuco & 236 & 9.323 & 126 & 1.800 & 6 & 198 & 34 & 764 \\
\hline Alagoas & 101 & 5.234 & 69 & ."" & 2 & 209 & 5 & 101 \\
\hline Sergipe & 100 & 4.121 & 17 & 203 & 9 & "". & 10 & "." \\
\hline Bahia & 274 & 9.935 & 10 & 411 & 3 & 299 & 2 & 367 \\
\hline Espírito Sto & 51 & 807 & 4 & 89 & 1 & 217 & 2 & "'?.' \\
\hline Rio de Janeiro & 191 & 6.805 & 92 & 1.650 & 8 & 71 & 33 & 1.184 \\
\hline São Paulo & 240 & 5.603 & 47 & 2.098 & 3 & 52 & 1 & 72 \\
\hline Paraná & 18 & 1.571 & 47 & 2.098 & 2 & 42 & 1 & "". \\
\hline Sta Catarina & 73 & 2.448 & 33 & 1.929 & 2 & 42 & 1 & 52 \\
\hline S.P do R.G.S. & 203 & 9.514 & 88 & 3.379 & 3 & 54 & 119 & 902 \\
\hline Minas Gerais & 378 & 121.700 & 142 & 370 & 42 & "". & 59 & 371 \\
\hline Goiás & 69 & 1.153 & 142 & 370 & 1 & 99 & 1 & 32 \\
\hline Mato Grosso & 15 & 549 & 7 & 169 & 1 & 59 & 1 & 32 \\
\hline
\end{tabular}

Fonte: ALMEIDA, José Ricardo Pires de. História da Instrução pública no Brasil p.120

No final do Império, houve o primeiro recenseamento brasileiro, em 1872, pelo qual ficamos sabendo quanto era a população do país: 10.112.000 habitantes. A província da Bahia tinha 1.379.616 moradores, $\mathrm{e}$ as onze paróquias que compunham a cidade do Salvador, 108.138 (MATTOSO,1992;87).

Apenas cerca de $1,23 \%$ da população brasileira e $0,8 \%$ da baiana estavam estudando em 1869. 
No ano de 1875 , segundo ALMEIDA $(1889 ; 168)$ a província da Bahia, por exemplo, possuía o seguinte número de escolas e alunos:

\begin{tabular}{l|cc|c|c|c|c|c|}
\hline $\begin{array}{l}\text { Tipo de Escola } \\
\text { (Bahia - 1875) }\end{array}$ & \multicolumn{4}{r|}{ HOMENS } & \multicolumn{2}{|c|}{ MULHERES } & \multicolumn{2}{r}{ TOTAL } \\
\hline Primária Pública & 308 & 11.853 & 120 & 4.864 & 428 & 16.717 \\
Primária Particular & 14 & 718 & 12 & 492 & 26 & 1.210 \\
Liceu Artes e Ofícios & - & - & - & - & 1 & 104 \\
Orfanato So Joaquim & - & - & - & - & 1 & 82 \\
Secundo Pública & - & - & - & - & 3 & 448 \\
Secundo Particular & - & - & - & - & 13 & 2.293 \\
\hline
\end{tabular}

Fonte: ALMEIDA, José Ricardo Pires de. História da Instrução Pública no Brasil p.168

Se usarmos a população de 1872, temos que, mesmo assim, apenas cerca de $1,5 \%$ da população provincial baiana estava freqüentando a escola em 1875.

Dados do IBGE sobre 1872 indicam $84,2 \%$ de analfabetos no Brasil e $81,9 \%$ na Bahia (sendo alfabetizada, complementarmente $15,8 \%$ da população brasileira e 18,1 \% da baiana)(IBGE, 1986,tabela 6: Classificação segundo o grau de instrução, p.13).

Era aproximadamente esta a situação educacional brasileira e baiana quando, a 5 de janeiro de 1878, tomou posse o gabinete chefiado pelo liberal João Uns Vieira Cansansão de Sinimbu, que teve no ministério do Império, Carlos Leôncio de Carvalho.

A reforma Leôncio de Carvalho

Carlos Leôncio de Carvalho era um professor de Direito em São Paulo quando foi chamado por João Uns Vieira Cansansão de Sinimbu (liberal moderado, que compôs o $27^{\circ}$ gabinete do Império, em 5 de janeiro de 1878, ficando até 27 de março de 1880) para ser o titular da Pasta do Império, à qual estava subordinada a Instrução Pública. AZEVEDO $(1964 ; 598)$ o considera o inovador de ensino mais audacioso e radical do período do Império.

Seu Decreto $n^{\circ}$ 6.884, de 20 de abril de 1878, (MJNI-OPMin, 1962; 180) alterou os regulamentos do Imperial Colégio Pedro 11, abolindo inclusive a obrigatoriedade do ensino religioso aí, permitindo assim aos acatólicos receberem o grau de bacharel sem o curso de instrução religiosa (AZEVEDO, 1964;599). 
A esse princípio de liberdade de consciência acrescentou ainda o da liberdade de ensino, tornando livre a freqüência do externato (MOACYR, 1937,v.2;17e TOBIAS, 1986;160).

No dia 6 de setembro deste ano, assinou o Decreto $n^{\circ} 7.031$

criando cursos noturnos para adultos nas escolas públicas de instrução primária do sexo masculino no município da Corte. Teriam duas horas de aula no verão, de outubro a março, e três horas no inverno, de abril a setembro, estando abertas à clientela masculina adulta - maiores de 14 anos - livre ou liberta. Aí se lecionariam as mesmas matérias das escolas diurnas. Havia, porém, um rigoroso sistema de punições e recompensas, estranhável, num liberal como ele, por impor mais dificuldades que facilidades aos adultos que pretendessem atingir a alfabetização (FREIRE, 1989;95/6).

O decreto 7.031 ligou-se certamente, segundo PAIVA (1987;71 e 313), à discussão da reforma eleitoral que então se fazia - e se concretizou tornando as eleições diretas no Gabinete Saraiva, em 1881 - e que introduzia a exigência de saber ler e escrever para ser eleitor. A ampliação das bases eleitorais dependeria, portanto, da multiplicação de escolas para adultos, que é o que este decreto pretendeu realizar.

No ano seguinte, com o decreto $n^{\circ} 7.247$, a 19 de abril de 1879, reforma o ensino primário e secundário no município da Corte e o superior em todo o Império. Jovem entusiasta das teorias da liberdade completa em matéria de ensino, Leôncio de Carvalho expressava logo em seu artigo 1 a estas idéias, o que fez com que o decreto ficasse sendo mais conhecido como o "Decreto do Ensino Livre":

É completamente livre o ensino primário e secundário no Município da Corte e o superior em todo o Império, salvo a inspeção necessária para garantir as condições de moralidade e higiene. (apud FREIRE, 1989; 108).

\section{Isto significava, em suas próprias palavras:}

Que todos os que se crêem capazes de o fazer possam ensi nar, sem provas oficiais de capacidade e sem autorização prévia;

Seja permitido a cada um expor livremente suas idéias, ensinar as doutrinas que julga verdadeiras pelos métodos que julgar mais convenientes;... .

Cada indivíduo poderá adquirir (instrução) no grau que Ihe for necessário, segundo seus interesses, sua vocação e sua condição social, recebendo-a dos professores de sua escolha, daqueles que Ihe 
inspirarem maior confiança (Leôncio de Carvalho, apud ALMEIDA, 1989;182/3)

Também aí decretou a incompatibilidade do professor com os empregos políticos ou administrativos e sugeriu a melhoria da condição do professorado dando-lhe as garantias de bem-estar e independência, aumentando os salários de modo a tornar a carreira mais vantajosa e invejável (apud ALMEIDA, 1989;184).

Seu decreto tornava ainda a instrução obrigatória para as crianças de ambos os sexos, abaixo de 14 anos, num raio de $1 \mathrm{~km}$ em torno de uma escola pública, para meninas, e de $1,5 \mathrm{~km}$ para meninos. $\mathrm{E}$ - 0 que é surpreendente para um império escravista - eliminou a proibição dos escravos freqüentarem as escolas públicas! (PAIVA,1987;71 e XAVIER/RIBEIRO/NORONHA, 1994;89)

Acrescentou ao antigo programa de instrução primária do primeiro grau (de seis anos de duração) as matérias

Desenho Linear e elementos de Música e ginástica. Para - segundo grau (dois anos de duração), seu programa acrescentava as noções de Álgebra e de Geometria, elementos de Física, de Química e de História Natural, noções gerais sobre os deveres do homem e do cidadão, explicações da Constituição Política do Império, além das noções de agricultura, horticultura, economia social para os meninos, economia doméstica para as meninas e, enfim, a prática de certos ofícios, para os meninos. (ALMEIDA, 1989;185)

O ensino religioso, além de não ser mais obrigatório, deveria ser ministrado em dias determinados, antes ou depois do horário escolar.

Determinou o período letivo nas escolas primárias de 10 e $2^{\circ}$ graus em dois turnos: das 9 às $12 \mathrm{~h}$ e das 13 às $15 \mathrm{~h}$, sendo que as crianças até 10 anos teriam aulas apenas até o meio dia. Também permitia que meninos até dez anos freqüentassem as escolas femininas, iniciando assim a co-educação. (FREIRE, 1989;109)

Estabeleceu a criação, para a instrução elementar das crianças de ambos os sexos, de Jardins da Infância em cada distrito do Município Neutro. Preconizava ainda haver neles uma caixa escolar, pequenas bibliotecas e museus escolares.

Propôs conceder aos institutos de instrução secundária que seguissem os mesmos programas de estudos do colégio Pedro II todas as prerrogativas de que este gozava, desde que a instituição pretendente já viesse funcionando regularmente por mais de sete anos e apre sentasse pelo menos 60 alunos graduados com o bacharelado em letras (MOACYR, 1937,v.2;200) 
Recomendou a criação de Escolas Normais em todas as províncias e para elas traçou novo plano, introduzindo em seu programa de estudos o Latim, o Inglês, o Alemão, o Italiano e a Retórica.

Após as escolas normais, Leôncio de Carvalho menciona as conferências pedagógicas, ou reuniões periódicas de todos os professores para conferenciarem e discutirem entre si sobre os melhores métodos de ensino e demais questões de interesse prático a ele concernentes (MOACYR, 1937,v.2;193). XAVIER/RIBEIRO/NORONHA (1994;90) lastimando que tais conferências e seminários pedagógicos para uma discussão permanente dos problemas educacionais brasileiros não tenham sido realizados.

O ministro sugeriu a conveniência de se instituírem escolas ambulantes ou de ensino por professores que vão de localidade em localidade levar a instrução aos meninos que, pela distância, se acharem privados do benefício da escola; este ensino deveria reduzir-se ao essencial: ler, escrever, contar (MOACYR, 1937 ,v.2; 187)

Leôncio de Carvalho pediu ainda a atenção do Legislativo para a necessidade de serem construídas casas apropriadas para funcionamento das escolas públicas.(MOACYR, 1937,v.2;187).

Chamou a atenção para a necessidade de criação de uma fonte de receita especial, com aplicação exclusiva à instrução, estabelecendo-se um imposto, denominado taxa escolar, à semelhança da que existia nos Estados Unidos, e que já fora sugerida por Tavares Bastos em sua obra "A Província". (MOACYR,1937,v.2;190)

Propôs a divisão dos cursos de Direito em duas seções: a das ciências jurídicas e a das ciências sociais (p.176). Considerava de grande utilidade a criação de cursos anexos à seção de ciências jurídicas para habilitar os notários públicos (MOACYR, 1937, v.2; 178). Seu Decreto permitia a associação de particulares para a fundação de escolas onde se ensinassem as matérias de qualquer curso oficial de ensino superior, sem que o governo interviesse em sua organização. Acrescentava que, funcionando tais instituições por sete anos consecutivos e podendo provar que pelo menos quarenta alunos obtiveram o grau acadêmico mediante exames no curso correspondente, o Governo poderia conceder o título de Faculdade Livre, com todos os privilégios e garantias de que goza a Faculdade ou Escola oficial. Esta concessão ficaria, porém, dependente de aprovação do Poder Legislativo (LOURENÇO FILHO,1954;49/50). 
Considerado por FREIRE $(1989 ; 107)$ um equívoco do idealismo liberal, o decreto do Ensino Livre, de Leôncio de Carvalho, foi posto em prática, mas como pouco depois este ministro deixou o cargo, teria havido uma diminuição da eficácia de suas novas medidas. Mas este decreto foi certamente conhecido pelos administradores da Instrução Pública nas províncias, sobretudo os liberais.

Leôncio de Carvalho pretendeu modificar o regulamento da Escola Politécnica, mas foi seu decreto neste sentido que provocou a sua demissão, segundo ALMEIDA (1989;192). Foi substituído em 4 de junho de 1879 por Francisco Maria Sodré Pereira, deputado (MJNIOPMin, 1962;177).

\section{o que foi feito da reforma proposta por Leôncio de Carvalho}

O Decreto do Ensino Livre foi encaminhado para a Assembléia Geral em 1878 e transformado em lei pelo Decreto 7.247, de 19 de abril de 1879 . O barão Homem de Meio, ministro do Império do Gabinete seguinte - também liberal, chefiado por José Antonio Saraiva, que sucedeu ao Gabinete Sinimbu a partir de 28 de março de 1880 - emitiu em maio um Aviso em que mencionava as disposições do Decreto do Ensino Livre que estavam sendo executadas na ocasião. Eram elas:

ENSINO PRIMÁRIO: os alunos acatólicos não são obrigados a freqüentar a aula de religião; o horário das aulas; nas aulas do sexo feminino só são recebidos alunos até dez anos de idade; caixa econômica escolar; limitação da quota do aluguel do professor que reside no mesmo prédio escolar; admissão gratuita dos filhos de professor, nos estabeleci

mentos de ensino secundário criados ou subvencionados pelo Estado, provado que o professor bem serviu durante dez anos no magistério; juramento prestado pelo professor será de acordo com a religião de cada um;

ENSINO SUPERIOR: freqüência livre e não chamamento à lição e sabatina; o indivíduo julgado inabilitado em qualquer matéria, seja ou não aluno do curso, poderá prestar exames na época própria seguinte e repeti10 quantas vezes quiser, guardado o intervalo de uma e outra época; cursos livres das matérias ensinadas nos estabelecimentos de ensino superior; o estudo do direito constitucional, civil, comercial e administrativo será sempre acompanhado de comparação da legislatura pátria com a dos povos cultos; para colação de grau não se exigirá dos acatólicos o 
exame de direito eclesiástico; permissão de inscrição às mulheres nas escolas de medicina, para as quais não haverá lugares separados; juramento na colação de graus acadêmico será conforme a religião do aluno. (MOACYR,

1937,v.2;21819).

Nada mencionou, portanto, a respeito da freqüência de escravos às escolas públicas, que, de tão adiantada, certamente não se concretizou. Esta reforma durou doze anos, até a reforma Benjamin Constant em 1890, segundo TOBIAS (1986;160).

Mas o Decreto do Ensino Livre, de Leôncio de Carvalho, inspirado em grande parte nas modernas idéias liberais norte-americanas, era considerado muito avançado para sua época, e talvez por isso não tenha conseguido implantar-se plenamente. Valeu, no entanto, porque muitas de suas idéias acabaram sendo, de fato, postas em prática; e ainda podemos afirmar que valeu sobretudo pelo fato de ter provocado os pareceres de uma comissão de Instrução Pública da Câmara, relatados por Ruí Barbosa, que com eles apresentou um projeto de lei para a educação nacional. Estes pareceres, de outro liberal como Leôncio de Carvalho, vão também ser considerados avançados e não serão adotados em sua totalidade, embora tenham influenciado alguns políticos em suas reformas educacionais.

\section{Os pareceres de Rui Barbosa}

Rui Barbosa nasceu em Salvador em 1840, filho de João José Barbosa de Oliveira, que fora Diretor de Instrução Pública; fez seus estudos secundários no Ginásio Baiano de Abílio César Borges, ingressou na Faculdade de Direito do Recife em 1866, mas se formou pela de São Paulo em 1870. Atuou como advogado na Bahia e filiouse ao Partido Liberal no grupo de Manuel Pinto de Sousa Dantas, junto com quem integrou o grupo de redatores do jornal Diário da Bahia. Foi eleito por este partido deputado provincial em 1877 e deputado geral em 1878, em cujo posto permaneceu até 1884. Participou das principais reformas que estavam sendo discutidas neste tempo e eram encampadas pelo Partido Liberal: a da instrução pública, cujo primeiro decreto fora o de Leôncio de Carvalho; a eleitoral (cujo texto redigiu), que acabou tornando-se lei no Gabinete Saraiva em 9 de janeiro de 1881, e a abolicionista, tendo Rui redigido o projeto apresentado em 1884 pelo senador Dantas propondo a localização provincial da propriedade escrava, o aumento do fundo de emancipação e a libertação incondicional dos sexagenários. Apenas a última parte deste projeto se converteria na chamada Lei Saraiva-Cotegipe, sancionada em 28 
de setembro de 1885 (BANDECCHI et alii, 1970;82), num gabinete já não mais liberal, e sim conservador.

Como deputado geral, participava da Comissão de Instrução da Câmara, a quem coube analisar e dar parecer sobre o Decreto do Ensino Livre de Leôncio de Carvalho. Rui foi exatamente o relator desta comissão e, diante da atualidade das opiniões liberais - também seguidas em grande parte por ele - emitidas no decreto, resolveu fundamentar-se em estatísticas e dados não só dos Estados Unidos como de vários outros países desenvolvidos, fazendo um verdadeiro trabalho de educação comparada, para justificar as opiniões apresentadas.

Em decorrência de algumas situações adversas, como o atraso na recepção de dados pretendidos e da impressão dos pareceres na Tipografia Nacional, os pareceres foram apresentados à Câmara tardiamente, quando já não havia mais o interesse político dos liberais no assunto (FREIRE, 1989;112). Seu Parecer sobre o ensino secundário e superior foi apresentado em 13 de abril de 1882 (gabinete Silva Campos) e o Parecer sobre o ensino primário e instituições complementares no dia 12 de setembro de 1882 (gabinete Paranaguá), ambos liberais, não tiveram andamento, nem os projetos de lei com eles apresentados foram sequer discutidos na Câmara.

Assim como Leôncio de Carvalho julgava que o velho regime de faltas, lições e sabatinas, que ainda hoje vigora nas academias, merece ser abolido (MOACYR,1937,v.2;172), também Rui, em vários momentos de seu parecer, criticava o ensino verbalista e repetitivo, centrado no professor, tentando moldar rigorosamente a lição do mestre pelo texto do livro, e industriar nos hábitos de uma reprodução estéril, pela frase inflexivel do compêndio e pela palavra servil do preceptor, o espírito do aluno (BARBOSA, 1946;v.X,t.11,37)

Apresentando dados da situação da instrução pública no país na ocasião e comparando-a com dados semelhantes aos dos países desenvolvidos, Rui, no seu comentário ao decreto do Ensino Livre, de fato pretendeu propor uma nova estrutura para o ensino brasileiro. Um dos princípios fundamentais para Rui era o da educação pelo Estado (IOURENÇO FllHO,1954;28)

Rui criticou o Decreto do Ensino Livre por ter sido feito e aprovado pelo poder executivo, quando a instrução seria matéria que deveria ser trabalhada pelo poder legislativo. Sugeriu, porém, a criação de um Ministério da Instrução Pública, caso em que o poder executivo poderia lidar com mais independência em relação à educação. 
Associou, como o fizera Carvalho, a gratuidade do ensino elementar - princípio constitucional no Brasil- ao princípio da instrução obrigatória, que ele propunha dever ocorrer dos 7 aos 13 anos, sendo que os que não houvessem, nessa idade, alcançado a escolaridade (primária elementar, média e superior) a ela atribuída, deveriam continuar obrigatoriamente na escola até os 15 anos; os que pretendessem encaminhar-se para escolas profissionais poderiam interromper a obrigatoriedade no final da escola primária média (NASCIMENTO, 1997;98).

Concordava com Leôncio de Carvalho quanto ao princípio da liberdade de consciência, propugnando pelo ensino laico. As aulas de religião, optativas, deveriam ser dadas no final do período escolar diário, por, no máximo, três vezes por semana.

Aceitava também a liberdade de ensino, fazendo-lhe porém restrições devido à necessidade absoluta de uma rigorosa e sistemática intervenção do Estado na organização e na vida do ensino nacional, da educação popular. Haveria liberdade de ensino, mas para se obter diplomas era necessário submeter-se aos exames nas escolas ou Estado ou então que as escolas particulares seguissem o mesmo programa oficial e fossem equiparadas às do Estado.

Preconizou a criação dos "Jardins de Crianças" para a educação pré-escolar, seguindo o método de ensino do Jardim Froebel.

No que se referia ao ensino primário, propôs uma seriação dife rente da do decreto; são dois níveis, de 4 e 2 anos, mas três níveis, cada um com 2 anos de duração. Indicou a necessidade de incluir aulas de ginástica em horários para elas reservados e relacionou as disciplinas a serem lecionadas, incluindo música e canto, desenho e, na turalmente, as ciências naturais, concordando com Leôncio de CarvaIho, já que os liberais defendiam a ciência como capaz de subjugar a natureza e efetivar os sonhos humanos descobertos pela razão (FREIRE,1989;132).

Considerou também inadmissível o horário em dois períodos na escola e recomendou nova distribuição do tempo escolar. No curso primário elementar (para crianças dos 7 aos 9 anos), oito tempos de trinta minutos de aula intercalados com sete tempos de quinze minutos de recreio; o curso primário médio (dos 9 aos 11 anos) com seis tempos de quarenta e cinco minutos, intercalados por cinco tempos de quinze minutos de recreio. Estes dois níveis teriam, portanto, no total uma sessão diária escolar de cinco horas e quarenta e cinco minutos. Já o curso primário superior (de 11 a 13 anos de idade) teria sete tempos de quarenta e cinco minutos de aulas intercalados por seis 
tempos de quinze minutos de recreio (total seis horas e quarenta e cinco minutos). Nos últimos dois anos do curso superior primário (de 13 a 15 anos) deveriam ser diminuídos os tempos do recreio ou acrescentados mais um tempo de quarenta e cinco minutos de aula (FREIRE,1989;139/140).

Criticou, porém, o decreto por ter incluído "lições de coisas" como uma matéria entre outras do programa e não como um método geral de estudos abrangendo o programa todo, sendo um processo ao qual deveriam subordinar-se todas as disciplinas (FREIRE,1989;129). Em 1881, Rui traduzira inclusive a obra de Allison Norman Calkins, Primary Object Lessons, com o título "Primeiras lições de coisas manual de ensino elementar para uso de pais e professores", que foi publicada apenas em 1886.

Foi contra a criação de caixas econômicas escolares propostas pelo Decreto, pois as crianças ainda não tinham condições de saber o real valor do dinheiro por não trabalharem para ganhá-lo.

Achava extremamente importante a formação de professores e determinou inclusive que as escolas normais tivessem a duração de quatro anos, em sistema de externato. Determinava também que seus alunos assinassem um compromisso de lecionar um certo número de anos em escolas públicas depois de formados, pois seria um modo de compensar o Estado em suas despesas com a sua formação.

Era contra os concursos para preenchimento de vagas, por achálos demasiadamente subjetivos, mas propôs um plano de carreira para o magistério: no fim do curso normal, mediante exame de grau, o aluno obteria o título de adjunto; depois de determinado tempo de prática de ensino, o exame de habilitação lhe conferiria o grau de professor depois de averiguar se possuía as qualidades inerentes ao mestre (FREIRE,1989;150)

Recomendou a fundação de bibliotecas e museus pedagógicos, onde quer que houvesse escolas normais e um Museu Pedagógico Nacional.

Julgou que o ensino médio, além do curso geral que levava ao bacharelado em ciências ou letras, deveria ter outros cursos de natureza técnico-profissional, tendo sugerido alguns deles Agrimensor e Diretor de Obras Agrícolas, Maquinistas, Mestre de Indústria, Relojoaria e Instrumentos de Precisão, Finanças e Comércio - considerados por Rui como necessários "à prosperidade da classe industrial ou mercantil" (NASCIMENTO, 1997;26) 
Preconizou a construção urgente de prédios escolares obedecendo aos princípios da higiene escolar e propôs a criação de um Fundo Escolar, com rendas de diversas origens, inclusive um imposto por pessoa.

Defendeu a criação de um Conselho Superior de Instrução Pública e a existência de inspetores gerais e escolares de distrito, aconselhando ainda a descentralização municipal através dos Conselhos Escolares de Paróquias.

\section{Conclusão}

O Decreto do Ensino Livre, apesar de muito avançado em alguns pontos, sofreu muitas críticas sobretudo pela introdução da livre freqüência. O visconde de Ouro Preto (Afonso Celso de Assis Figueiredo, liberal, ex-ministro do Império) declarou ser este regime totalmente dissonante dos meios de ensino vigentes no país. O diretor da Faculdade de Direito do Recife, João Vieira de Araújo, achou que este Decreto piorou a situação, pois a freqüência naturalmente diminuiu muito. Atéo Conselho de Estado, chamado a opinar, julgou não ter validade o Decreto 7.247 na parte referente à livre freqüência (N ISKI ER, 1989; 158/ 9).

Em 1881, o presidente da província da Bahia, Antonio Araújo de Aragão Bulcão, fez uma reforma da instrução pública na província em que aproveitou várias idéias progressistas do Decreto 7.247, como a introdução do desenho linear, lições de coisas e das ciências naturais no currículo do curso primário e normal, mas não, naturalmente, a livre freqüência (NUNES,1999b;5). Era uma visão liberal, sem dúvida, porém bem mais moderada, a que vigorou na Bahia até a república: o "Regulamento Bulcão".

E também Rui Barbosa, em seus pareceres, se bem que comentasse criticamente o Decreto do Ensino Livre, de Leôncio de Carvalho - que se baseava sobretudo nas idéias liberais norte-americanas - e tivesse trazido contribuições do que ocorria em vários outros países, inspirando sua metodologia nos pedagogos considerados mais avançados na ocasião como Comenius (ainda atual, apesar de seiscentista), Froebel, Pestalozzi, Herbart ou mesmo Spencer, utilizou muitas idéias norte-americanas e chegou mesmo a traduzir a obra de um norte americano para que fosse adotada entre nós. Rui foi, de certa maneira, um precursor das idéias da Escola Nova que apenas na década de 20 do século XX seriam debatidas e postas em prática aqui. Isto porque centrava na criança e em suas etapas evolutivas todo o ensino. 
Procurava perceber suas necessidades e interesses e enfatizava sobretudo a atividade do próprio aluno como meio eficaz de aprendiza- I gemo

As idéias de Rui foram aproveitadas apenas na República, tendo seus Pareceres sido fonte de inspiração para a reforma educacional desencadeada por Manoel Vitorino Pereira, 10 presidente do Estado da Bahia no regime republicano e posta em prática a partir do início do ano letivo de 1890 (NUNES, 1999;14). Pena que seu governo só durou até o fim de abril de 1890 e o seu sucessor mandou suspender sua reforma e voltar-se ao "Regulamento Bulcão", de 1881.

Em nível nacional, a reforma educacional proposta por Benjamim Constant, enquanto Ministro de Instrução Pública, Correios e Telégrafos, em novembro de 1890, também sofreu influência dos Pareceres e opiniões de Rui Barbosa, mas, com a morte do ministro em 1891, sua execuçãofoisuspensa.

Eruditíssimos pareceres, belo estudo de educação comparada, magnífico quadro da educação na época, no Brasil e em vários países, tudo porém sem ter tido uma aplicação efetiva. Guardou-se para estudos acadêmicos até o momento em que suas idéias foram ultrapassadas pela evolução econômica, social e educacional e hoje já é estudado de forma crítica, mas contextualizando-se o que era possível imaginar e fazer na época em que Rui viveu e atuou.

\section{REfERÊNciAS BibLioGRÁficAs}

ALMEIDA, José Ricardo Pires de. História da Instrução pública no Brasíl (1500-1889) Trad. Antônio Chizzotti. São Paulo:EDUC/ Brasília:INEP/MEC,1989. 365 p. AZEVEDO, Fernando de. A Cultura Brasíleira. Introdução ao estudo da cultura no Brasíl. 4a ed. São Paulo: Melhoramentos, 1964. $803 \mathrm{p}$.

BANDECCHI, Brasil, ARROYO, Leonardo e ROSA, Ubiratan. Novo dicionário de História do Brasil. São Paulo: Melhoramentos, 1970. 621 p. il.

BARBOSA, Rui. Reforma do ensino primário e várias instituições complementares da instrução pública. In OBRAS COMPLETAS DE RUI BARBOSA Volume X - 1883. Prefácio de Americo Jacobina Lacombe. Rio de Janeiro: Ministério da Educação e Saúde. Tomo I, 1947.351 p.; Tomo li, 1946.401 p.; Tomo 111, 1947.312 p. e Tomo IV, 1947. $281 \mathrm{p}$.

FREIRE, Ana Maria Araújo. Analfabetismo no Brasil - da ideologia da interdição do corpo à ideologia nacionalista, ou de como deixar sem ler e escrever desde as Catarinas (Paraguaçu), Filipas, Madalenas, Anas, Genebras, Apolônias e Grácias até os Severinos 1534-1930. São Paulo: Cortez / Brasília,DF: INEP, 1989. 236 p. (Biblioteca da educação. Série I - Escola; v.4) 
HAIDAR, Maria de Lourdes Mariotto. "A instrução popular no Brasil antes da república" in BREJON, Moisés (org.). Estrutura e funcionamento do ensino de $1^{\circ}$ e $2^{\prime}$ graus Leituras. 24" ed. São Paulo: Pioneira, 1995 p.39-56.

IBGE. Série Estatísticas Retrospectivas. Vol. I Repertório Estatístico do Brasil - Quadros retrospectivos (Separata da ANUÁRIO ESTATíSTICO DO BRASIL - Ano V 1939/40) Edição fac-similar (original publicado em 1941) Rio de Janeiro: IBGE, 1986. LOURENÇO FILHO. A pedagogia de Rui Barbosa. São Paulo: Melhoramentos, 1954. $130 \mathrm{p}$.

MATTOSO, Katia M. de Queirós. Bahia, século XIX - um província no Império. Rio de Janeiro: Nova Fronteira, 1992.747 p.

MINISTÉRIO DA JUSTIÇA E NEGÓCIOS INTERIORES. Organizações e programas ministeriais - regime parlamentar no Império. (MJNI-OPMin) 2" ed. Rio de Janeiro: Arquivo Nacional, 1962. 469 p.

MOACYR, Primitivo. A instrução e o império - subsídios para a História da Educação no Brasil. $1^{\circ}$ vol. 1823-1853 São Paulo: Cia. Editora Nacional,1936. 614 p. 2 vol. Idem, ibidem, 1854-1888. Mesmo local e editora, 1937, $614 \mathrm{p}$.

NASCIMENTO, Terezinha Quaiotti Ribeiro do. Pedagogia liberal modernizadora Rui Barbosa e os fundamentos da educação brasileira republicana. Campinas, S.P.:

Autores Associados, 1997. 120 p. (Col. Memória da educação)

NISKIER, Arnaldo. Educação brasileira 500 anos de História: 1500-2000. São Paulo:

Melhoramentos, 1989. $646 \mathrm{p}$.

NUNES, Antonietta de Aguiar. "O primeiro governador da Bahia republicana e seu projeto de reforma educacional", trabalho apresentado no XIV Encontro de Pesquisa educacional do Nordeste dia 17 de junho de 1999 e publicado em seus Anais, em CD. $16 \mathrm{p}$.

NUNES, Antonietta de Aguiar. "As reformas educacionais na província da Bahia durante o Império Brasileiro" in Revista GESTÃO EM AÇÃO v.2 n.1 janljun 1999a p. 7398.

NUNES, Antonietta de Aguiar. "A reforma da educação baiana em 1881: o Regulamento Bulcão" trabalho apresentado no IV Congresso de História da Bahia de 27 setembro a $1{ }^{\circ}$ de outubro de 1999b. $11 \mathrm{p}$.

I PAIVA, Vanilda Pereira. Educação popular e educação de adultos. São Paulo: Loyola, I 1987. 368 p.

!TOBIAS, José Antônio. História da educação brasileira. 3" ed. São Paulo: IBRASA, I 1986. 349 p.

।XAVIER, Maria Elizabete 1 RIBEIRO, Maria Luiza e NORONHA, Olinda Maria. História da Educação - a escola no Brasil. São Paulo: FTD, 1994. 304 p. (Col. Aprender e . ensinar). 